University of Wollongong

Research Online

Faculty of Engineering and Information

Faculty of Engineering and Information

Sciences - Papers: Part B

Sciences

2016

Caregivers Time Utilization Before and After the Introduction of an Electronic Nursing Documentation System in a Residential Aged Care Facility

Esther Naliaka Munyisia

University of Wollongong, enm258@uowmail.edu.au

Ping Yu

University of Wollongong, ping@uow.edu.au

David M. Hailey

University of Wollongong, dhailey@uow.edu.au

Follow this and additional works at: https://ro.uow.edu.au/eispapers1

Part of the Engineering Commons, and the Science and Technology Studies Commons

Research Online is the open access institutional repository for the University of Wollongong. For further information contact the UOW Library: research-pubs@uow.edu.au 


\section{Caregivers Time Utilization Before and After the Introduction of an Electronic Nursing Documentation System in a Residential Aged Care Facility}

\section{Keywords}

utilization, before, after, introduction, electronic, nursing, documentation, system, residential, aged, care, facility, time, caregivers

Disciplines

Engineering | Science and Technology Studies

\section{Publication Details}

Munyisia, E. Naliaka., Yu, P. \& Hailey, D. M. (2016). Caregivers Time Utilization Before and After the Introduction of an Electronic Nursing Documentation System in a Residential Aged Care Facility. Journal of Ergonomics, 6 (4), 1-4. 


\title{
Caregivers Time Utilization Before and After the Introduction of an Electronic Nursing Documentation System in a Residential Aged Care Facility
}

\author{
Esther Naliaka Munyisia ${ }^{1}$, Ping $\mathrm{Yu}^{2^{\star}}$ and David Hailey ${ }^{2}$ \\ ${ }^{1}$ School of Psychology and Public Health, Latrobe University, Melbourne, Victoria 3086, Australia \\ ${ }^{2}$ School of Computing and Information Technology, The University of Wollongong, Northfields Ave, Wollongong, Australia
}

*Corresponding author: Ping Yu, Centre for IT-Enabled Transformation, School of Computing and Information Technology, The University of Wollongong, NSW 2522, Australia, Tel: +61242214212; E-mail: ping@uow.edu.au

Received date: Mar 14, 2016; Accepted date: Jun 07, 2016; Published date: Jun 14, 2016

Copyright: (c) 2016 Munyisia EN. This is an open-access article distributed under the terms of the Creative Commons Attribution License, which permits unrestricted use, distribution, and reproduction in any medium, provided the original author and source are credited.

\begin{abstract}
Background: Despite increasing research interest in caregivers' interaction with technology, there has been no attempt to investigate how the introduction of an electronic nursing documentation system in a residential aged care facility may affect caregivers' use of their time.
\end{abstract}

Objective: To assess how caregivers use their time before and after the introduction of an electronic nursing documentation system in a residential aged care facility.

Methods: An observational work sampling study was undertaken with caregivers at 2 months before, and at 3,6 , 12 and 23 months after the implementation of an electronic nursing documentation system.

Results: During the first 12 months after implementation, the proportion of time spent by personal carers on documentation increased whereas the proportions on direct care and communication decreased. At 23 months, these proportions had returned to pre - implementation levels. The proportion of time spent by recreational activity officers on documentation increased, that on communication decreased and the proportion on direct care remained stable during the first 12 months after implementation. The proportion of time on documentation returned to the preimplementation level after 23 months. Changes in proportions of time on other activities were not directly associated with the introduction of the electronic system.

Conclusion: Caregivers in a residential aged care facility may take over a year to integrate and use an electronic nursing documentation system in their daily work. Organisations implementing such systems should acknowledge the level of resources and time needed for the workforce to fully absorb the system and integrate it into their daily residential aged care service delivery.

Keywords: Electronic nursing documentation; Electronic health record; Impact; Nurse; Residential aged care facility; Long-term care; Nursing home

\section{Introduction}

Electronic systems are increasingly being introduced into healthcare settings. In residential aged care facilities (RACFs), electronic systems have the potential to improve care delivery while reducing caregivers' documentation load and increasing the time available for residents' care [1-2].

In Australia, our audit of the official aged care accreditation reports shows that about one-third of the RACFs that are accredited by the government have used electronic systems to support the management of residents' records and delivery of care. The reasons for the remaining two thirds of the RACFs not using electronic systems range from high cost of implementation to uncertainty of how the systems will impact on caregivers' work [3-4]. Therefore understanding how an electronic system may affect caregivers' work is useful in encouraging acceptance of the system by the caregivers and in motivating the aged care organisations to invest in ICT innovations.

A number of studies assessing the effects of these systems on nursing work have been conducted in hospitals and their focus has mainly been on time spent on activities by nursing staff [5-7]. For example, six months after the implementation of an electronic documentation system in an intensive care unit of a surgical ward, Wong et al. found that nursing staff spent more time on direct care (i.e., patient examination), indirect care (i.e., report and exchange of patient information), administration (i.e., staff meetings), and housekeeping activities (i.e., room set-up) compared with the time spent on these activities using a paper-based system. Their time on documentation duties (i.e., recording of hourly output) decreased significantly after implementation [8]. Little attempt, however, has been made to assess the effect of an electronic documentation system on the work of caregivers in an RACF. Thus, there is limited understanding about how these systems may affect the time caregivers spend on activities in this setting. 
In this paper, we present the results of a 25 -month longitudinal study on caregivers' time utilization before and after the introduction of an electronic nursing documentation system in an RACF.

\section{Methods}

The study is part of a larger project on changes in caregivers' work following the introduction of an electronic nursing documentation system in an RACF in Australia. Participants in this study were personal carers (PCs) and recreational activity officers (RAOs) working on a morning shift (6.45am to $3.15 \mathrm{pm})$. The caregivers working on afternoon or night shifts, allied healthcare staff, and registered nurses assigned to administrative tasks or supervision of the PCs were excluded from the investigation.

This study was conducted using an observational work sampling technique at two months before, and at 3, 6, 12 and 23 months after the introduction of the electronic system. Each study period lasted five days (Monday, Tuesday, Wednesday, Saturday and Sunday) and observations were made during the morning shift on each day of the study.

\section{Caregivers' activities}

The caregivers' activities were identified and recorded using a predetermined set of tasks. These include direct care activities, medication management, communication activities, documentation activities, indirect care activities, personal activities, in-transit and other tasks. Direct care activities included all nursing activities performed in the presence of a resident and/or relative, for example, assessment and hygiene. Medication activities included all medication related activities including preparation, administration, and documentation. Communication activities included all activities related to oral communication such as sharing information about a resident. Documentation activities included all activities related to paper-based and computer-based documentation such as taking records from the storage place and inputting a username and password into a computer. Indirect care activities included tasks that are not resident specific such as identifying correct supplies and packing supplies to a trolley. Personal activities included activities unrelated to residents for example, meal breaks and making telephone calls. In-transit included time between tasks such as time spent walking in corridor. Others included tasks not classified anywhere. These activities were adapted from those specified in previously published instruments [9-11]. A detailed account of the procedures followed in identifying the activities, validation of these activities and assessment of inter-rater reliability are available in Munyisia et al. [12].

\section{Data collection procedures}

Prior to the first period of study, the observer (ENM) met the caregivers in their morning shift handover meetings and gave them information sheets about the study to read, understand and ask any questions. The observer also explained the purpose and method of study to the caregivers and allayed any fears about the investigation. After each meeting, the observer invited the caregivers to participate in the study and they all accepted by signing consent forms.

During data collection, observations were made every five minutes. The observer followed the same route on each round of observation and recorded all tasks being undertaken by each caregiver on a tabular data collection tool using a unique code number allocated to each task Brief communication between the observer and a caregiver to clarify an activity being undertaken was allowed when necessary. When a caregiver was not found on a given round of observation, a dash (-) was recorded to denote missing. But if another caregiver on the floor indicated that his or her colleague, for instance was on break, then this activity was recorded accordingly. This methodology was applied at all the measurement periods [13]

At 6 months and 12 months after implementation, structured interviews were held with the caregivers to assess their experiences with the electronic system. In total, six PCs and two RAOs participated during the two interview periods. Each interview was audio-taped and then transcribed verbatim.

\section{Data analysis procedures}

Data were entered into MS Excel 2003 spread sheets and exported to SPSS version 18.0 ( Inc., Chicago, IL, USA) for analysis using descriptive statistics. Differences in proportions of time spent on activities before and after the implementation of the electronic nursing documentation system were identified using Pearson's chi-square test. A significance level for each test was set to 0.05. However, given the multiple comparisons in this study (32 independent comparisons for the PCs and 16 for the RAOs), Bonferroni correction was used to adjust for the multiplicity. Thus, results from these comparisons are presented as adjusted p-values. Hence, a p-value less than 0.002 for the PCs and a p-value less than 0.003 for the RAOs were considered to be statistically significant [14].

For the interviews, the transcripts were analysed using an inductive content analysis method as described by Elo and Kyngas [15]. Transcripts were open-coded, line-by-line to identify terms or events that were similar and appeared to shed light on the caregivers' experiences with the electronic documentation system. Categories emerged from these terms and events. The categories from different transcripts were then compared and grouped into broader higher order categories. The content of these categories was then used to abstract major themes from which to draw conclusions for this study [16].

\section{Results and Discussion}

A total of 10,947 activities were recorded for the PCs (See Table 1) and 1,500 for the RAOs (See Table 2) [14]. The proportion of time spent on documentation by the PCs increased at most measurement periods during the first 12 months after implementation. This increase may be a result of the changes in the PCs' documentation practice. Instead of documenting the care provided to each resident at least once in a week, as per the policy of the RACF, the frequency of their documentation increased after system implementation. During this period, the proportion of time spent on direct care activities reduced. This suggests that the PCs were still in the learning stage of how to use the electronic nursing documentation system in their work. This finding, however, is contrary to that of Cherry et al. [17] who found that some caregivers perceived they spent longer time on direct care duties after the introduction of an electronic system. This variation in the findings may be attributed to differences in the study design, measurement periods, and the electronic documentation system in use. At 23 months, the PCs' proportions of time on documentation and direct care activities had returned to pre-implementation levels.

The percentage of time spent on these activities by the RAOs remained unchanged at most measurement periods after implementation of the electronic system. The finding on documentation activity may partly be attributed to the RAOs' 
Citation: Munyisia EN, Yu P, Hailey D (2016) Caregivers Time Utilization Before and After the Introduction of an Electronic Nursing Documentation System in a Residential Aged Care Facility. J Ergonomics 6: 168. doi:10.4172/2165-7556.1000168

Page 3 of 4

preferred mode of obtaining information about a resident in a workshift. According to the interviews, the RAOs prefer oral communication to written nursing notes regardless of the documentation system in use.

The caregivers' proportion of time on communication activities remained unchanged at almost all the measurement periods after the implementation of the electronic nursing documentation system. This may be due to lack of change in the role of verbal communication between caregivers in aged care. Indeed, in a previous study, we found that caregivers in an RACF highly value their face-to-face interaction for successful care delivery [13]. Changes in proportions of time on other activities were not directly associated with the introduction of the electronic nursing documentation system.

The results of this study, however, may not be generalizable to other RACFs because the study was conducted at a single RACF using a particular electronic documentation system. Effective acceptance and use of such a system by the caregivers depends on the quality of the electronic documentation system, its ease of use and training provided to the caregivers.

\begin{tabular}{|c|c|c|c|c|c|c|c|c|c|}
\hline \multirow[t]{3}{*}{ Activities } & \multicolumn{5}{|c|}{$\%$ (number of observations) } & \multirow{2}{*}{\multicolumn{4}{|c|}{$\begin{array}{l}\text { Chi-square test between measurement periods }(\alpha \\
=0.002) \mathrm{b}\end{array}$}} \\
\hline & \multicolumn{5}{|c|}{ Measurement periods a } & & & & \\
\hline & $2 n=2549$ & $3 n=2331$ & $6 n=2364$ & $12 n=1623$ & $23 n=2080$ & $2-3$ & $2-6$ & $2-12$ & $2-23$ \\
\hline Communication & $42.6(1086)$ & $40.2(937)$ & $37.2(880)$ & $38.6(627)$ & $39.9(830)$ & 0.088 & $0.001^{*}$ & 0.011 & 0.063 \\
\hline Indirect care & $6.3(161)$ & $7.3(169)$ & $8.8(211)$ & $4.3(70)$ & $6.4(134)$ & 0.194 & $0.001^{*}$ & 0.006 & 0.861 \\
\hline Direct Care & $14.9(381)$ & $10.9(255)$ & $9.4(223)$ & $12.1(196)$ & $14.4(299)$ & $<0.001^{*}$ & $<0.001^{*}$ & 0.009 & 0.584 \\
\hline Documentation & $11.8(300)$ & $10.4(243)$ & $18.1(428)$ & $15.8(257)$ & $10.2(212)$ & 0.136 & $<0.001^{*}$ & $<0.001^{*}$ & 0.089 \\
\hline Personal & $5.3(134)$ & $12.4(289)$ & $7.8(184)$ & $9.0(146)$ & $12.2(254)$ & $<0.001^{*}$ & $<0.001^{*}$ & $<0.001^{*}$ & $<0.001^{*}$ \\
\hline $\begin{array}{l}\text { Medication } \\
\text { management }\end{array}$ & $9.3(237)$ & $5.4(127)$ & $5.9(139)$ & $5.4(88)$ & $4.1(85)$ & $<0.001^{*}$ & $<0.001^{*}$ & $<0.001^{*}$ & $<0.001^{*}$ \\
\hline In-transit & $9.4(239)$ & $11.9(278)$ & $12.3(291)$ & $11.6(189)$ & $12.1(254)$ & 0.004 & $0.001^{*}$ & 0.019 & $0.002^{*}$ \\
\hline Others & $0.4(11)$ & $1.4(33)$ & $0.3(8)$ & $3.1(50)$ & $0.7(14)$ & $<0.001^{*}$ & 0.599 & $<0.001^{*}$ & 0.269 \\
\hline \multicolumn{10}{|c|}{$\begin{array}{l}2=2 \text { months before the implementation of the system; } 3=3 \text { months after implementation; } 6=6 \text { months after implementation; } 12=12 \text { months after implementation; } \\
\text { and } 23=23 \text { months after implementation. }\end{array}$} \\
\hline \multicolumn{10}{|c|}{$\begin{array}{l}\text { b Comparison of the proportion of time spent on each category of activities before and after the implementation of the electronic system. For instance, a comparison of } \\
\text { the proportion of time spent on activities } 2 \text { months before and } 3 \text { months after the implementation of the system is denoted by ' } 2-3^{\text {'. }}\end{array}$} \\
\hline \multicolumn{10}{|c|}{$\begin{array}{l}\text { * Statistically significant outcome of chi-square test. A p-value less than } 0.002 \text { was considered statistically significant. For example, in the row for communication, } \\
\text { there is a notable difference in proportion of time spent between } 2 \text { months before and } 6 \text { months after the implementation of the system }(p=0.001) \text {. }\end{array}$} \\
\hline \multicolumn{10}{|c|}{$\mathrm{n}=$ total observations } \\
\hline
\end{tabular}

Table 1: PCs' proportion of time on activities before and after the implementation of the electronic nursing documentation system.

\begin{tabular}{|c|c|c|c|c|c|c|c|c|c|}
\hline \multirow[t]{3}{*}{ Activities } & \multicolumn{5}{|c|}{$\%$ (number of observations) } & \multirow{2}{*}{\multicolumn{4}{|c|}{$\begin{array}{l}\text { Chi-square test between measurement periods }(\alpha= \\
0.003) \mathrm{b}\end{array}$}} \\
\hline & \multicolumn{5}{|c|}{ Measurement periods a } & & & & \\
\hline & $2 n=379$ & $3 n=305$ & $6 n=160$ & $12 n=374$ & $23 n=282$ & $2-3$ & $2-6$ & $2-12$ & $2-23$ \\
\hline Communication & $54.6(207)$ & $44.6(136)$ & $46.9(75)$ & $45.2(169)$ & $41.8(118)$ & 0.009 & 0.100 & 0.010 & $0.001^{*}$ \\
\hline Direct Care & $36.1(137)$ & $20.7(63)$ & $40.0(64)$ & $35.0(131)$ & $35.1(99)$ & $<0.001^{*}$ & 0.398 & 0.748 & 0.782 \\
\hline Documentation & $4.7(18)$ & $18.7(57)$ & $3.1(5)$ & $9.6(36)$ & $5.0(14)$ & $<0.001^{*}$ & 0.394 & 0.010 & 0.899 \\
\hline In-transit & $4.5(17)$ & $16.1(49)$ & $10(16)$ & $10.2(38)$ & $18.1(51)$ & $<0.001^{*}$ & 0.015 & $0.003^{*}$ & $<0.001^{*}$ \\
\hline \multicolumn{10}{|c|}{$\begin{array}{l}\text { † Only those activities recorded five times or more at each measurement period are presented. } \\
\text { a The same explanation for measurement periods as in Table } 1 \text {. } \\
\text { b The same explanation as in Table } 1 \text {. }\end{array}$} \\
\hline
\end{tabular}

Table 2: RAOs' proportion of time on activities before and after the implementation of the electronic nursing documentation system. 
Citation: Munyisia EN, Yu P, Hailey D (2016) Caregivers Time Utilization Before and After the Introduction of an Electronic Nursing Documentation System in a Residential Aged Care Facility. J Ergonomics 6: 168. doi:10.4172/2165-7556.1000168

Page 4 of 4

\section{Conclusion}

The findings suggest that it may take over 12 months for caregivers in an RACF to completely adopt and integrate an electronic documentation system into their daily work. Thus, organisations implementing such systems need to provide adequate human resources and learning time for the workforce to adapt to the new system. The organisations can develop strategies to support and accelerate this adaptation process. Another important finding is that an electronic documentation system cannot replace the role of verbal communication in aged care service provision.

\section{Acknowledgement}

The authors would like to thank the Personal Carers and Recreational Activity Officers at Albion Park Rail residential aged care facility, for their consent to participate in this study. The managers of Warrigal Care Aged Care Organization (the CEO Mark Sewell, Care Systems Officer Dylan Hepworth, Research Officer Renshaw Shandell and the Residential Service Manager Helen Pavlik) are acknowledged for providing the support needed to complete the study.

\section{References}

1. Institute of Medicine (2004) Keeping Patients Safe: Transforming the Work Environment of Nurses. National Academies Press, Washington DC.

2. Munyisia EN, Yu P Hailey D (2011) The changes in caregivers' perceptions about the quality of information and benefits of nursing documentation associated with the introduction of an electronic documentation system in a nursing home. International Journal of Medical Informatics 80: 116-26.

3. Yu P, Comensoli N (2004) An exploration of the barriers to the adoption of information technology in Australia aged care industry. Proceedings of the Health Informatics Conference Brunswick East, Vic, Australia.

4. Cherry B, Carter M, Owen D, Lockhart C (2008) Factors affecting electronic health record adoption in long-term care facilities. Journal of Healthcare Quality 30: 37-47.

5. Bosman RJ, Rood E, Oudemans-van Straaten HM, Van der Spoel JI, Wester JP, et al. (2003) Intensive care information system reduces documentation time of the nurses after cardiothoracic surgery. Intensive Care Medicine 29: 83-90

6. Hakes B, Whittington J (2008) Assessing the impact of an electronic medical record on nurse documentation time. Computers, Informatics, Nursing 26: 234-241.

7. Gabr H (2010) The effect of computerized patient record on nurses' time spend on documentation in inpatient units. International Journal of Academic Research 2: 108-120.

8. Wong DH, Gallegos Y, Weinger MB, Clack S, Slagle J, et al. (2003) Changes in intensive care unit nurse task activity after installation of a third-generation intensive care unit information system. Critical Care Medicine 31: 2488-2494.

9. Bosman RJ, Rood E, Oudemans-van Straaten HM, Van der Spoel JI, Wester JPJ, et al. (2003) Intensive care information system reduces documentation time of the nurses after cardiothoracic surgery. Intensive Care Medicine 29: 83-90.

10. Korst LM, Eusebio-Angeja AC, Chamorro T, Aydin CE, Gregory KD (2003) Nursing documentation time during implementation of an electronic medical record. Journal of Nursing Administration. 33: 24-30.

11. Pelletier D, Duffield C (2003) Work sampling: valuable methodology to define nursing practice patterns. Nursing and Health Sciences 5: 31-38.

12. Munyisia E, Yu P, Hailey D (2010) Development and testing of a work measurement tool to assess caregivers' activities in residential aged care facilities. In: Safran C, MEDINFO Proceedings of the 13th World Congress on Medical Informatics.

13. Munyisia EN, Yu P, Hailey D (2011) How nursing staff spend their time on activities in a nursing home: an observational study. Journal of Advanced Nursing. 67: 1908-1917.

14. Munyisia EN, Yu P, Hailey D (2013) Caregivers' time utilization before and after the introduction of an electronic nursing documentation system in a residential aged care facility. Methods of Information in Medicine 52: 403-410.

15. Elo S, Kyngas H (2008) The qualitative content analysis process. Journal of Advanced Nursing 62: 107-115.

16. Munyisia EN, Yu P, Hailey D (2012) The impact of an electronic nursing documentation system on efficiency of documentation by caregivers in a residential aged care facility. Journal of Clinical Nursing 21: 2940-2948

17. Cherry JC, Ford WF, Peterson LT (2011) Experiences with electronic health records: early adopters in long-term care facilities. Health Care Management Review 36: 265-274. 